Int. J. Dev. Biol. 48: 793-804 (2004)

doi: $10.1387 / \mathrm{ijdb} .041885 \mathrm{jc}$

\title{
Analysis of mouse eye development with chimeras and mosaics
}

\author{
J. MARTIN COLLINSON*1, ROBERT E. HILL ${ }^{2}$ and JOHN D. WEST ${ }^{3}$ \\ ${ }^{1}$ School of Medical Sciences, University of Aberdeen, Scotland, ${ }^{2}$ Comparative and Developmental Genetics Section, MRC Human Genetics \\ Unit, Edinburgh, Scotland and ${ }^{3}$ Division of Reproductive and Developmental Sciences, Genes and Development Group, University of
} Edinburgh, Scotland, UK

\begin{abstract}
Analysis of experimental mouse chimeras (chimaeras) and mosaics provides a means of investigating patterning and differentiation within the developing mammalian eye. Chimeric and mosaic mice carry two or more genetically distinct cell populations and extend the repertoire of analytical tools available to the geneticist. Here we review the impact these techniques have had on our understanding of eye organogenesis. Chimeras and mosaics are routinely used to investigate cell lineages, patterns of growth and gene function, and provide a means to clear analytical hurdles that otherwise limit standard genetic approaches. In particular, chimeras are used to investigate the roles of genes in tissues that do not develop in conventional mutant or knock-out mice, to test whether genes act cell autonomously or non-autonomously in different tissues and to dissect tissue-tissue interactions in less tractable, complex systems. Chimeras, in which cells of different genetic composition are mixed at a fine-scale cellular level, may provide qualitatively different data from mosaic mice with conditional knockouts. The uses of chimeras, Cre-loxP mosaics and in vitro tissue recombination for study of ocular organogenesis are compared. Wider use of mosaics and chimeras should provide further insights into eye development.
\end{abstract}

KEY WORDS: eye, chimera, chimaera, mosaic, clonal analysis, chimeric rescue, cell autonomous gene action

\section{Introduction}

The mammalian eye is a complex developmental system, with contributions from tissues of disparate embryological origins, dependent on several embryological inductive events requiring tissue-tissue interactions, and complicated by rapid morphogenesis. Many developmental genes are expressed in more than one ocular tissue, and some of the genes expressed in the eye have fundamental roles elsewhere that lead to early developmental failure in mutants and make conventional gene knockouts uninformative for analysis of later stages of eye development. Hence, an understanding of eye organogenesis requires rigorous genetic analysis, posing developmental questions about cell lineages, tissue morphogenesis, and autonomy of gene action. Here, we review the roles that mouse chimeras and mosaics have played in dissecting these developmental processes.

\section{Production and analysis of mouse chimeras and mosaics}

\section{Chimeras}

A chimera is a composite organism with two or more genetically distinct populations of cells that are derived from more than one zygote. This article considers the uses of experimentally produced primary chimeras, where the distinct cell populations are combined early in development (usually by embryo aggregation or blastocyst injection), so all tissues may be chimeric. The production of mouse aggregation chimeras was devised by Tarkowski (1961) and involves recovery of two genetically distinct 8-cell stage embryos, removal of their zonae pellucidae, aggregation, culture to the blastocyst stage and surgical transfer to the uteri of pseudopregnant recipients for further development. In addition chimeras can be produced using cultured embryonic stem (ES) cells combined with embryos by aggregation, co-culture techniques or (more frequently) blastocyst injection (Gardner, 1968).

Optimal use of mouse chimeras requires that the distinct cell populations differ for a combination of genetic markers that provide qualitative, quantitative and spatial information about the composition of different tissues. Ideally the genetic markers which are used to distinguish cells from the different aggregated embryos should be developmentally neutral (i.e. they do not themselves influence ocular development), should be expressed cell-autonomously (such that their presence or absence reliably identifies the origin of the cell) and be relatively easy to detect at the required

Abbreviations used in this paper: ES, embryonic stem; GPI, glucose phosphate isomerase; RPE, retinal pigment epithelium.

\footnotetext{
*Address correspondence to: Dr. J. Martin Collinson. School of Medical Sciences, University of Aberdeen, Foresterhill, Aberdeen, AB25 2ZD, Scotland.
} Fax: +44-1224-55-5719. e-mail: m.collinson@abdn.ac.uk 

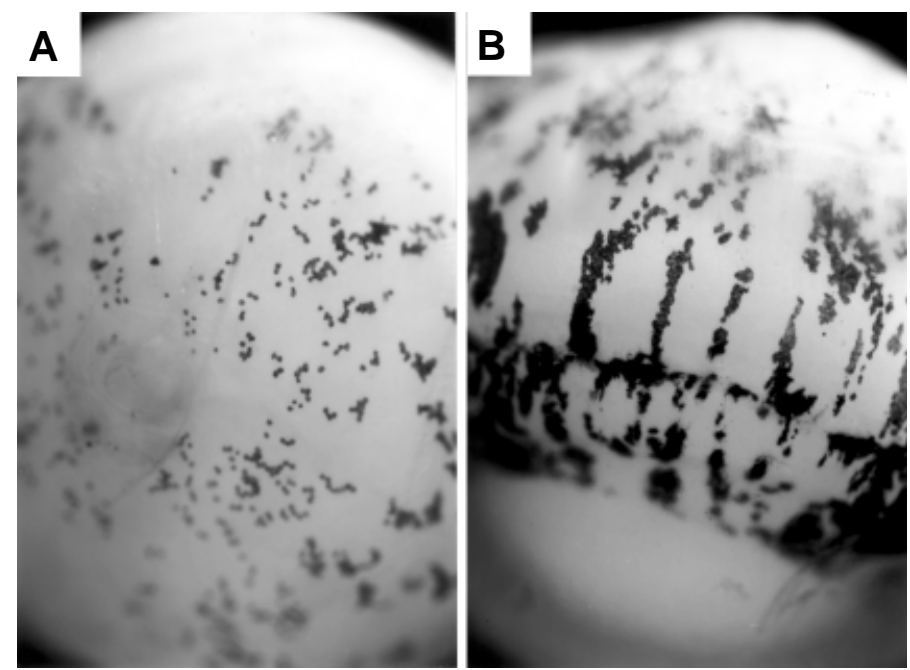

Fig. 1. Patterns of proliferation and growth in the retinal pigment epithelium. (A) The back of an adult pigmented $\leftrightarrow$ albino chimeric eye, showing small irregularly distributed patches in the retinal pigment epithelium (RPE). (B) Side-view of an adult pigmented $\leftrightarrow$ albino eye showing stripes of pigment in the RPE (centre) near where it meets the iris (from West, 1999).

level of analysis (in fresh tissue, fixed whole-mounts or histological sections). A common strategy is to combine embryos that differ for pigment markers, Gpi1 variants (encoding the ubiquitous enzyme glucose phosphate isomerase, GPI1) and one or more transgenic markers. Pigment markers provide a simple means of identifying which individuals are chimeric and allow spatial analysis of cell distributions in the retinal pigment epithelium (RPE). GPI electrophoretic variants can be used for quantitative analysis of tissue composition (Chapman et al., 1972; Gearhart and Mintz, 1972; West and Flockhart, 1994). Other molecular and biochemical genetic approaches have been used but GPI is widely favoured because the enzyme activity is ubiquitous, stable and simple to analyse. Although the contributions of the two cell populations to different chimeras varies widely, tissues within an individual chimera usually have a similar composition, so GPI analysis of several tissues usually gives a good guide to the overall composition of a chimera.

Fig. 2. Two-dimensional reconstructions of serial sections of RPE in pigmented $\leftrightarrow$ albino chimeras and the neural retina in $r d / r d \leftrightarrow+/+$ chimeras. (A,B) Chimeric RPEs showing clusters of pigmented cells radiating from the optic nerve head, which probably represent descendent clones. Pigmented and albino cells appear less mixed at the periphery in (B) (also see Fig. 1B) (Reproduced with permission from Sanyal and Zeilmaker, 1977). (C) Two-dimensional reconstruction of the RPE and neural retina from a $\mathrm{rd} / \mathrm{rd} \mathrm{c} / \mathrm{c} \leftrightarrow+/+\mathrm{C} / \mathrm{C}$ chimera showing both the areas of degenerated neural retina and the pigmented RPE cells. Solid lines represent normal neural retina; dashed lines represent intermediate degeneration of neural retina; dotted lines represent completely degenerated neural retina. The small black squares below the section lines represent pigmented RPE cells. There is no concordance between the distribution of normal neural retina (solid lines) and pigmented (C/C) RPE cells. Areas of predominantly normal $(+/+)$ and predominantly degenerated $(\mathrm{rd} / \mathrm{rd})$ neural retina appear to radiate from the central region near the optic nerve head. (Reproduced with permission from LaVail and Mullen, 1976).
A variety of histological, histochemical and immunohistochemical markers have been used for spatial analysis of chimeras (Gardner, 1984; Kusakabe et al., 1988; Ponder, 1987; West, 1984; Weinberg et al., 1985; Yoshiki et al., 1991) and DNA in situ hybridisation has also been used to detect species-specific satellite DNA sequences in Mus caroli $\leftrightarrow$ Mus musculus chimeras (Rossant and Chapman, 1983; Siracusa et al., 1983; Williams and Goldowitz, 1992). However, transgenic markers are now more commonly used. These include the highly reiterated $\mathrm{Tg}(\mathrm{Hbb}-\mathrm{b} 1) 83 \mathrm{Cl} / \mathrm{t}$ transgene, which can be detected in histological sections by DNA in situ hybridisation (Keighren and West, 1993; Lo, 1986), and transgenes that express ubiquitously either lacZ, such as Gt(ROSA)26Sor(ROSA26) (Friedrich and Soriano, 1991), or green fluorescent protein (GFP) (Hadjantonakis et al., 1998a; Pratt et al., 2000).

\section{Mosaics}

A genetic mosaic is similar to a chimera except that the genetically distinct cell populations arise from a single zygote. Females, heterozygous for $\mathrm{X}$-linked genes, are $\mathrm{X}$-inactivation mosaics since functional mosaicism arises after random X-chromosome inactivation occurs early in development (Lyon, 1961). Mouse X-inactivation mosaics can be generated easily by appropriate genetic crosses. Although no endogenous X-linked variants provide good cellular markers for spatial analysis in eyes, appropriate markers have been produced by mutagenesis and transgenesis experiments. The first useful X-linked cellular marker was Is $(\operatorname{In} 7 ; \mathrm{X}) 1 \mathrm{Ct}$ (Cattanach's translocation), resulting from the insertion of an inverted piece of chromosome 7 into the X chromosome (Cattanach, 1961). The inserted length of chromosome 7 includes the wild-type $C$ allele of the albino locus. Homozygous albino female mice $(c / c)$ that are hemizygous for the $\operatorname{ls}(\ln 7 ; X) 1 \mathrm{Ct}$ insertion have variegated coat and eye pigment (Deol and Whitten, 1972; West, 1976a). A number of transgenic markers have now been incorporated into the
A

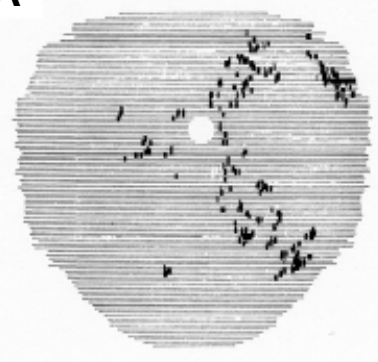

B

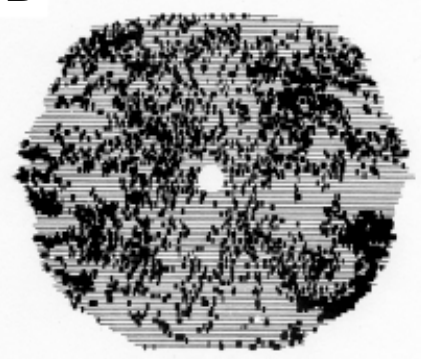

C

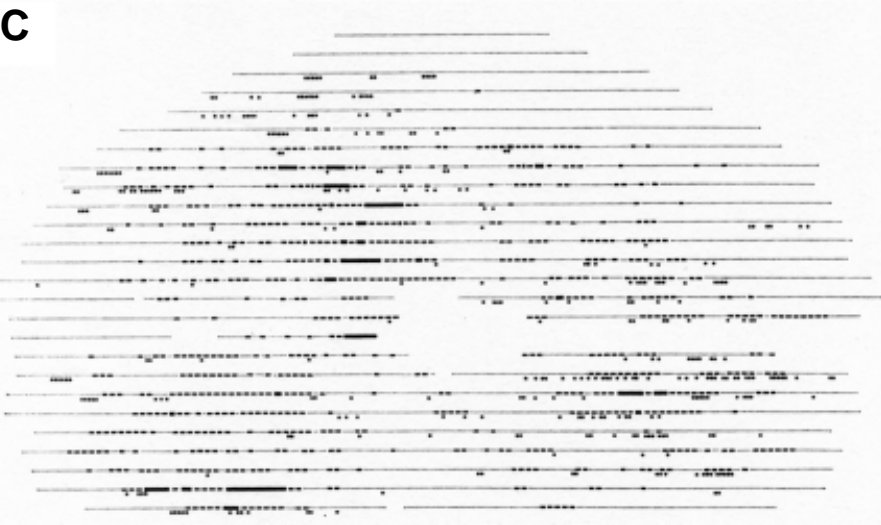


X-chromosome which allow analysis of X-inactivation mosaicism of unpigmented tissues. These include the lac $Z$ transgenic strain H253 (Tan etal., 1993; Tan and Breen, 1993) and GFP transgenics Tg(CMV-GFP)1Nagy (Hadjantonakis et al., 1998b) and Tg(CMVGFP)1Jae (Eggan et al., 2000).

The pink-eyed unstable mutation ( $p^{u(n)}$ ) has a DNA duplication which mediates somatic reversion to wild-type, producing mosaicism with patches of pigmented $p^{+/ u n}$ cells in a largely unpigmented $p^{u n / u n}$ RPE (Brilliant et al., 1991). Most other genetic mosaics used for studies of mouse development have been produced by transgenic methods. Exposure of mouse embryos to retroviruses results in transgenic mosaicism which provides a lineage marker in descendents of the infected cells (Soriano and Jaenisch, 1986; Turner et al., 1990). Mosaic lacZ expression has also been produced by engineering an inactive lac $Z$ transgene with an internal duplication. This 'laac $Z$ 'transgene undergoes intragenic homologous recombination at a low frequency to restore the active lac $Z$ transgene and so generates lac $Z$ mosaicism (Nicolas et al., 1996). Conventional autosomal transgenes may also generate mosaic expression as an unintentional consequence of position effect variegation (Dobie et al., 1997). In addition, conditional knockouts, produced using Cre-loxP technology induce mosaicism that may be generalised or restricted to one or a few tissues (Betz et al., 1996; Rossant and Spence, 1998).

\section{Analysis of organogenesis \& cell mixing during eye development}

\section{Retinal pigment epithelium}

The simple 2-dimensional distribution of pigmented and albino cells in a chimeric or mosaic retinal pigment epithelium (RPE) reflects the extent of cell mixing during development but retrospective estimation of the number of founder clones contributing to the RPE is more difficult. Spatial analysis of variegated patterns requires distinction of 'patches', 'coherent clones' and 'descendent clones', which are defined as follows. A patch is a group of cells of like genotype which are contiguous at the time of consideration, a coherent clone is a group of clonally related cells which have remained contiguous throughout development and a descendent clone is any group of clonally related cells irrespective of whether they remain contiguous (Nesbitt, 1974; West, 1976a, 1978a,b; West et al., 1997). Each founder cell produces a descendent clone but these may fragment into smaller coherent clones or merge with neighbouring coherent clones of the same genotype, to form visible patches comprising several coherent clones.

The mean size of coherent clones can be estimated from the mean patch size by correcting for the effects of the proportions of the two cell populations, in the mosaic or chimeric RPE, on clone aggregation (Roach, 1968; West, 1975, 1976a). An early histological study of chimeras and $X$-inactivation mosaics suggested that between E12.5 and the adult, the number of coherent clones in the RPE increased about 3-fold and the mean number of cells per coherent clone increased by 4 to 4.5 -fold (West, 1976a). Although such estimates of clone sizes and numbers may not be accurate in some situations (Schmidt et al., 1986) they still provide a valid means of comparing different groups of mosaics or chimeras (West et al., 1997; West, 1999).

In adult, pigmented $\leftrightarrow$ albino chimeras, the retinal pigment epithelium (RPE) is usually obscured by pigment in the choroid but
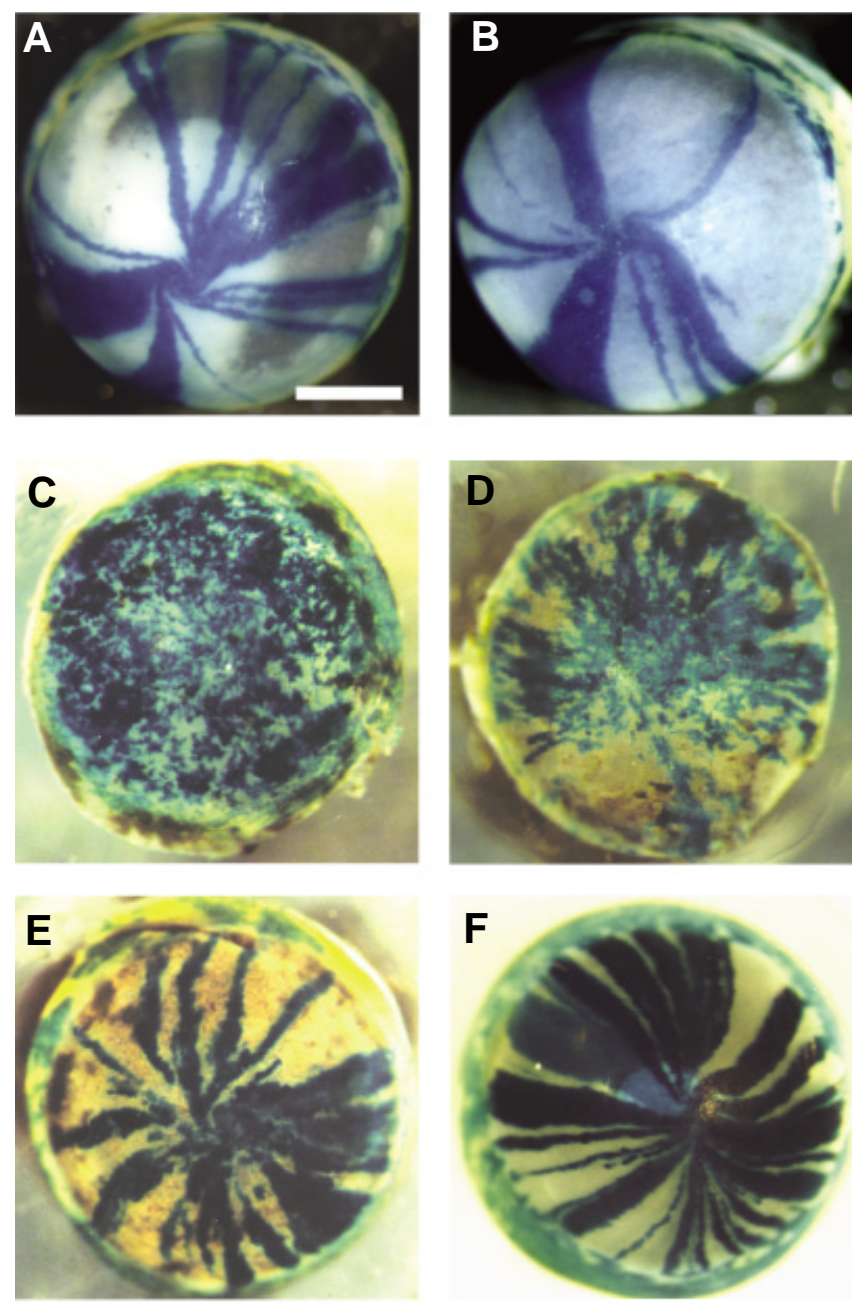

Fig. 3. Chimeric and mosaic analysis of growth and cell migration in the murine cornea. $(\mathbf{A}, \mathbf{B})$ Radial stripes in the corneal epithelium of adult lac $Z^{+}$ $\leftrightarrow$ lacZ ${ }^{-}$chimeric eyes stained with X-gal. (C-F) Development of radial stripes in the corneal epithelia of female $X$-inactivation mosaic mice, hemizygous for the H253, X-linked lacZ transgene. Stripes replace an initial pattern of randomly orientated patches. Eyes are from mice at 3 weeks (C), 7 weeks (D), 10 weeks (E) and 20 weeks (F). (Reproduced from Collinsonet al., 2002).

in some chimeras the choroid is predominantly unpigmented, which allows the RPE to be visualised directly. In the proximal RPE (near the optic nerve head) the pigmented and albino cells are usually arranged as small patches, often clustered within broadly defined radial sectors, whereas in the distal RPE (towards the iris) there are larger patches, arranged as radial stripes (Figs. 1, 2A,B). The distribution of pigmented and albino cells in chimeric RPE was examined in more detail by 2-dimensional reconstructions from serial sections (Sanyal and Zeilmaker, 1977) (Fig. 2 A,B) and whole mount preparations (Schmidt et al., 1986; Bodenstein and Sidman, 1987b). The broad radiating clusters probably represent descendent clones that were fragmented into smaller coherent clones proximally but remained less fragmented distally.

The formation of clearer stripes at the distal periphery (Figs. 1B, 2B) was explained by an elegant combination of computer modelling, mitotic analysis and analysis of chimeras and mosaics (Bodenstein, 1986; Bodenstein and Sidman, 1987a,b). Computer simulation 

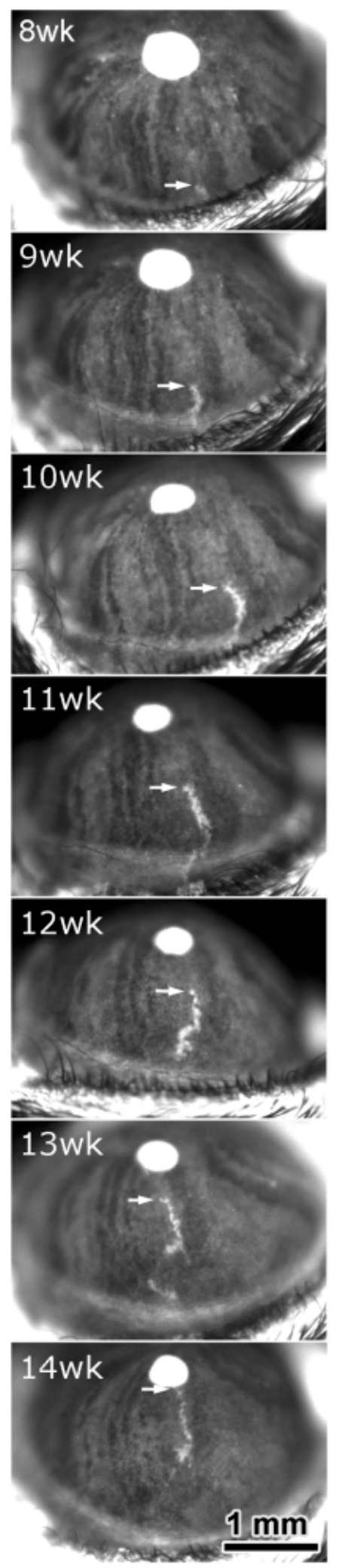

Fig. 4. Cell migration in the cornea. Time lapse sequence of centripetal cell movement of a brightly fluorescent GFP-positive patch of corneal epithelial cells in a mosaic Tg(GFPU)5Nagy transgenic mouse between 8 and 14 weeks. The arrow indicates the leading edge of the patch of cells. (Reproduced with permission from Nagasaki and Zhao, 2003). predicted that extensive cell mixing would occur if dividing cells were scattered throughout the tissue during RPE growth. Conversely, if cell divisions were mostly confined to the edge of the growing tissue little cell mixing was predicted so radial stripes would form at the growing edge. Mitotic activity in the RPE was then shown to be widespread at $\mathrm{E} 13$ but between $\mathrm{E} 13$ and $\mathrm{P} 7$ it became progressively more restricted to the distal edge, implying that the peripheral (distal) stripes were formed during the later growth stage when dividing cells were confined to the edge thus reducing cell mixing. This reduction in cell mixing later in development is consistent with the earlier evidence, discussed above, for an increase in mean coherent clone size between E12.5 and the adult.

\section{Corneal epithelium}

Striking radial stripes have been reported in the corneal epithelium of adult chimeras and $X$-inactivation mosaics carrying lac $Z$ transgenes (Collinson et al., 2002) and mosaic GFP transgenic mice (Nagasaki and Zhao, 2003). The stripes in the corneal epithelium were much more marked than those seen in the periphery of the RPE spanning, in some instances, the full radius of the cornea (Fig. 3), and arose after birth. At three-weeks, LacZ mosaics had a pattern of randomly orientated patches rather than stripes. Stripes only emerged at the periphery at around 5 weeks and reached the centre by about 8 weeks (Fig. 3). The corneal epithelium is maintained throughout adult life by stem-like cells (limbal stem cells - LSCs) which reside around the edge of the cornea and produce progeny that migrate centripetally to replace cells lost during normal life. The radial stripes in mosaics and chimeras reflect this centripetal migration of corneal epithelial cells, as was confirmed by an elegant time-lapse study of movement of groups of GFP-positive cells in mosaic GFP transgenic mice (Nagasaki and Zhao, 2003) (Fig. 4). It is now clear that development of the corneal epithelium produces randomly orientated patches of cells in neonates which are subsequently replaced by cells derived from LSCs at the periphery of the cornea.

\section{Neural retina}

Organogenesis in the neural retina is complex and involves interactions of many cell types. The adult neural retina is arranged in concentric layers including six classes of neurons and Müller glia, all derived from pluripotent retina progenitor cells (Cepko et al., 1996). Chimeras incorporating cells homozygous for a retinal degeneration mutation of the Pde6b gene (phosphodiesterase $6 \mathrm{~B}$, formerly $r d$ ) as a histological marker suggested that descendent clones in the neural retina are arranged as clusters of patches of mutant and wild-type cells radiating in sectors from near the optic nerve head to the ora serrata (Fig. 2C) (Mintz and Sanyal, 1970; Mintz, 1971; LaVail and Mullen, 1976). These original observations using retinal degeneration as a lineage marker are supported by more recent illustrations of similar distributions seen after lac $Z$ staining of whole-mount chimeric retinas (compare Fig. 5A with Fig. 2C; also see Figs 2a-e in Reese et al., 1999). One problem with using retinal degeneration as a morphological lineage marker in chimeras was that there were regions where degeneration was intermediate between wild-type and mutant (Fig. 2C). The use of modern cellular markers has shown that coherent clones span the full thickness of the neural retina as columns (see below), confirming the suggestion that the intermediate regions of retinal degeneration resulted from blur- 
ring of the original boundaries between columns of mutant and wild-type cells after degeneration occurred (West, 1976b; Mullen, 1978).

Approaches using either recombinant retrovirus-mediated transgenic mosaics, chimeras or $\mathrm{X}$-inactivation mosaics showed that marked cell populations were arranged in stripes or columns spanning the entire thickness of the retina (Turner and Cepko, 1987; Turner et al., 1990; Williams and Goldowitz, 1992; Reese et al., 1995) (Fig. 5 B,C). (These columns are orientated perpendicularly to the original sectors of descendent clones.) Moreover, these studies showed that each coherent clone can produce all the differentiated cell types. Further analysis with X-inactivation mosaics and chimeras showed that, for four of the six retinal cell types (cone photoreceptors, amacrine cells, horizontal cells and ganglion cells), individual cells are also dispersed tangentially (Reese et al., 1995; Reese and Tan, 1998; Fig. 5D). This tangential dispersal occurs over short distances characteristic of the cell type, which argues against passive displacement (Reese et al., 1999).

The picture that emerged from studies with chimeras and mosaics is that during the early phases of optic cup formation the founder cells produce descendent clones that radiate outwards. As the layers of the neural retina stratify, further proliferation produces coherent clones, which form columns spanning the full depth of the retina, from the photoreceptors to the ganglion cell layer. Subsequently some cells disperse laterally.

\section{Chimeric analysis of genetic control of eye develop- ment}

Mutations in developmental genes often lead to an early interruption of organogenesis (e.g anophthalmia) or embryonic lethality precluding the analysis of later roles for the gene in specific organs. Chimeras composed of populations of wild-type cells and cells carrying a gene mutation of interest will commonly develop to appropriate embryonic stages such that mutant cells get the opportunity to contribute to tissues that do not form in the mutant mice. Mutant cells may be excluded from, or behave abnormally in, tissues where normal gene function is required. Hence by analysing the distribution and phenotype of mutant cells in chimeras the impact that a developmental gene has on cellular function can be determined.

Chimeras are the 'classic' tools for determining cell autonomy and non-autonomy of gene action in any particular tissue. The function of a developmental gene in a cell that expresses it is said to be cell autonomous if activity of the gene is required within that cell for it to fulfil its normal developmental programme. One would imagine, for example, that transcription factors and genes involved with signal transduction pathways will have a number of cell autonomous roles. A non-autonomous role for a developmental gene would be a situation where activity of the gene in one cell is required to direct normal development of another cell, for example a gene encoding a secreted molecule that directs the development of neighbouring cells or tissues in a paracrine manner. Developmental genes may have both cell autonomous and non-autonomous functions - a transcription factor may have non-autonomous roles through regulation of expression of secreted molecules. In chimeras comprising a mixture of wild-type and mutant cells, only the mutant cells show the mutant phenotypic effect if the gene acts cell autonomously (e.g. they may be absent, depleted in numbers or abnormally distributed). If the gene does not act cell autonomously the wild-type cells may rescue the mutant cells so that neither show an abnormal phenotype or, conversely, both mutant and wild-type cells may be affected.

The production of chimeric embryos containing wild-type cells intermixed with mutant cells puts the two cell populations in competition with each other. Their intimate mixing may in these cases allow fine-scale analysis of cell-cell and tissue-tissue interactions and may demonstrate subtle developmental defects in the mutants.

\section{Analysis of cell autonomous versus non-autonomous re- quirement for developmental genes}

The power of chimeric analysis to diagnose autonomy of gene action is maximised if:

1) the expression pattern of the gene of interest is known;
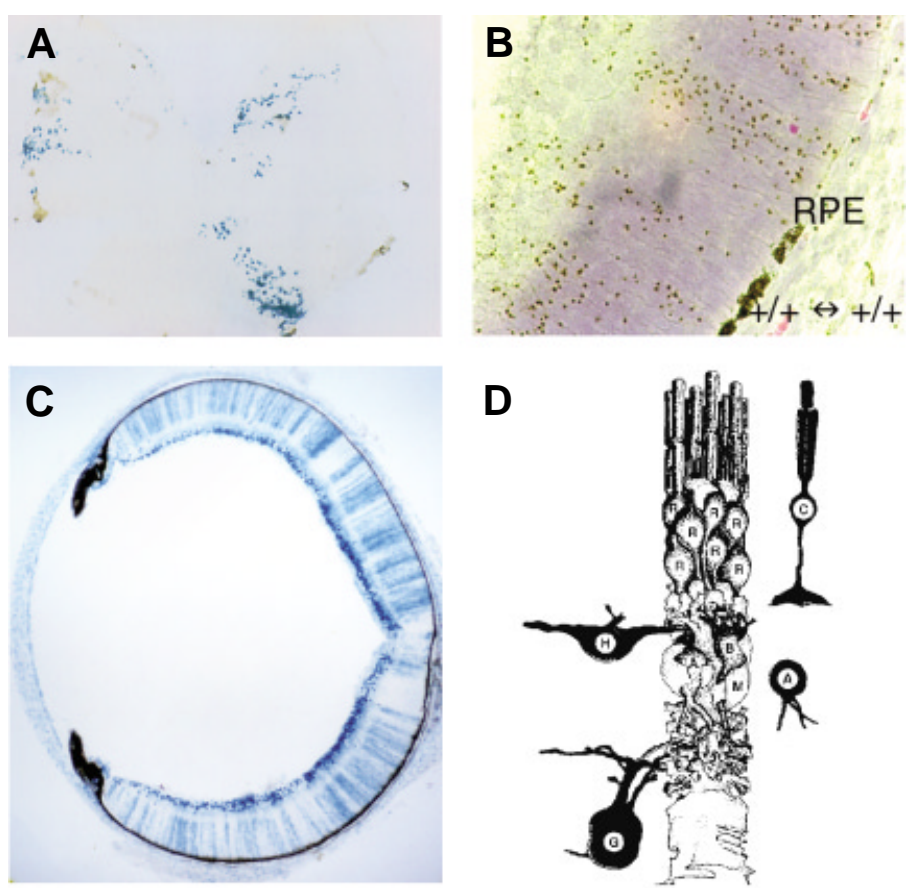

Fig. 5. Clonal growth in the neural retina. (A) A neural retina flat-mount preparation, from a lacZ $Z^{+} \leftrightarrow$ lacZ- mouse chimera, stained for ß-galactosidase, showing radiating patches of lacZ-positive cells (blue). (Reproduced from Reeseetal., 1999, with permission). (B) A section from an E12.5 mouse chimera marked with the reiterated $\beta$-globin transgene $\mathrm{Tg}(\mathrm{Hbb}-\mathrm{b} 1) 83 \mathrm{Clo}$. Stripes of transgenic neuroblast cells, detected by DNA in situ hybridisation and visualised as small brown spots in the nucleus, span the full depth of the developing neural retina. Patches of pigmented cells are labelled in the RPE. (Reproduced from Collinson et al., 2001) (C) A section from a newborn (P1) $X$-inactivation mosaic, mouse eye (female, hemizygous for the H253, Xlinked lacZ transgene). The eye was stained for ß-galactosidase and shows stripes of lacZ-positive cells that span the neuroblast layer and tangential dispersion of the cells in the ganglion cell layer. In 3-dimensions the stripes appear as columns. (Colour version of figure from Reese et al., 1999; reproduced with permission). (D) Diagrammatic representation of a clone of cells spanning the neural retina, showing coherent radial alignment of the rod cells $(R)$, bipolar cells $(B)$ and Müller glial cells $(M)$, and the local tangential dispersion of individual cone cells $(C)$, horizontal cells $(H)$, amacrine cells (A) and ganglion cells (G). (Based on Reichenbachet al., (1994), reproduced from Reese and Tan (1998) with permission). 

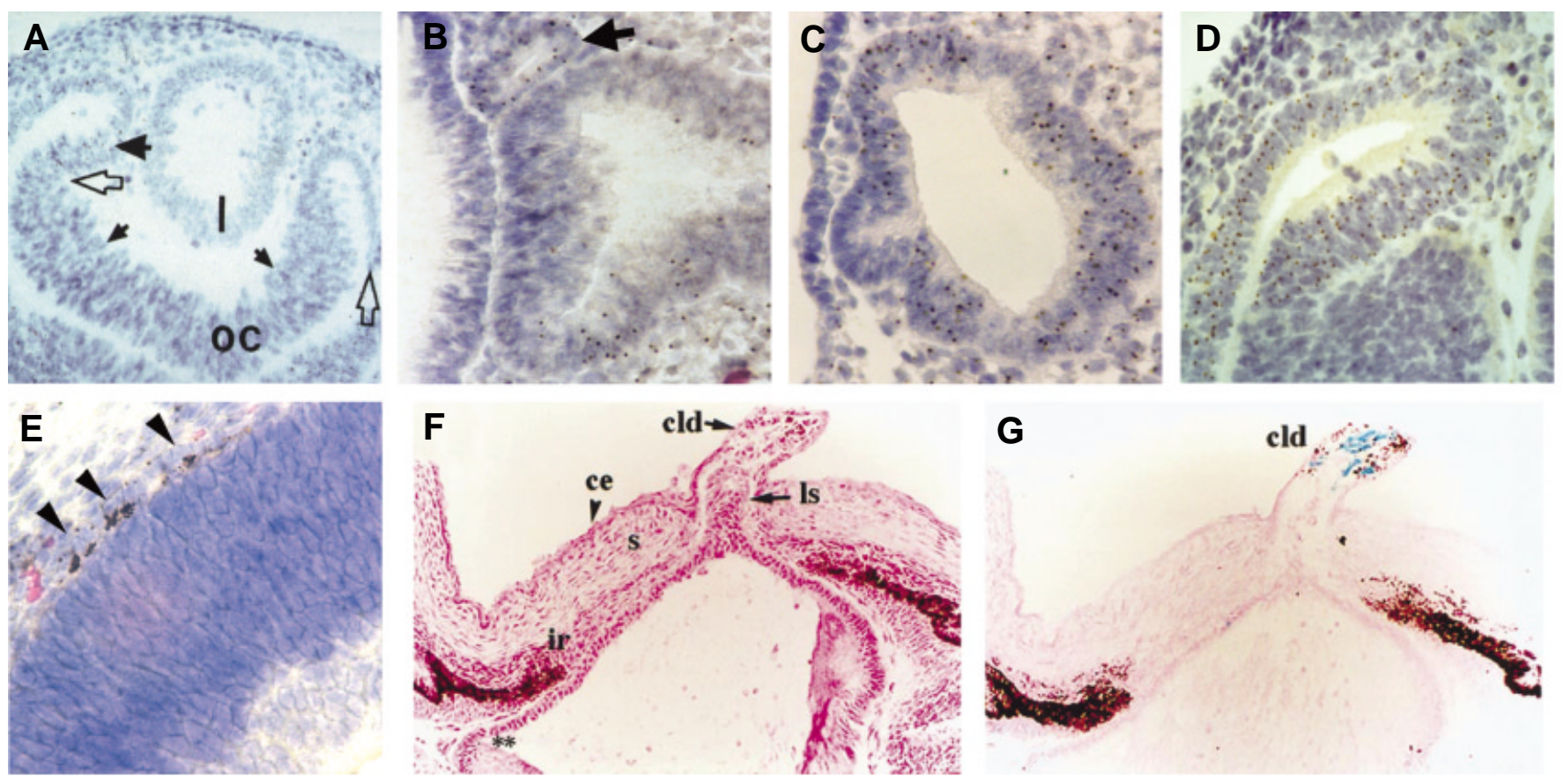

Fig. 6. Distribution and phenotype of mutant cells in chimeric eyes. (A) The lens (I) of an E12.5 Pax6 $6^{+/+} \leftrightarrow$ Pax $6^{-/}$chimera. Pax6 ${ }^{-1}$ cells are identified by the presence of a brown spot in the nucleus after DNA-DNA in situ hybridisation to visualise the Tg(Hbb-b1)83Clo (Tg) marker transgene. The lens is entirely composed of Pax6 ${ }^{+/+}, \mathrm{Tg}^{-}$cells. (From Quinn et al., 1996). (B) 'Exclusion' of an ectopic vesicle of Pax6 ${ }^{-1}$, Tg ${ }^{+}$cells (arrow) from the distal optic vesicle of an E9.5 Pax6 ${ }^{+/+} \leftrightarrow$ Pax $^{-1-}$ chimera. (C) Optic vesicle of an E9.5 Pax6 ${ }^{+/+} \leftrightarrow$ Pax6 ${ }^{-1}$ chimera with a higher percentage of Pax6 ${ }^{-1}$ cells than in (B). The optic vesicle is segregated into regions of purely $\mathrm{Pax} 6^{+/+}$or $\mathrm{Pax} 6^{-/}$cells. Only the Pax $6^{+/+}$region of the distal optic vesicle has maintained contact with the head surface ectoderm. (B, C. From Collinson et al., 2000). (D) Segregated regions composed purely of Pax6 $6^{+/+}$or Pax6 $6^{-1-}\left(\mathrm{Tg}^{+}\right)$cells in the retina of an E12.5 Pax6 ${ }^{+/+} \leftrightarrow$ Pax6 ${ }^{-/}$chimera. (From Quinn et al., 1996). (E) Pigmented Pax6 ${ }^{-/}$cells (arrows) in the RPE of an E16.5 Pax6 ${ }^{+/+} \leftrightarrow$ Pax6 $^{-/}$chimera. (From Collinson et al., 2003). (F,G) Persistent lens stalk in the cornea of an E18AP- $2 \alpha^{+/+} \leftrightarrow$ AP- $2 \alpha^{-1-}$ chimera (F). Blue X-gal staining (G) reveals the presence of AP-2 $\alpha^{-1-}$, lacZ ${ }^{+}$ cells correlates with the lento-corneal dysgenesis (F, G. Reproduced with permission from West-Mays et al., 1999). Key: I, lens; Is, lens stalk; cld, corneal lenticular defect; oc, optic cup; ce, corneal epithelium; s, corneal stroma.

2) the gross contribution of mutant cells to the chimera can be assayed by, for example, GPI analysis and

3) the genotype of all cells in the chimera can be identified in a way that allows a quantitative analysis of their distribution.

Some earlier chimera experiments investigated the differentiation or degeneration of the lens and retina without prior knowledge of the genes underlying the mutations of interest, and without transgenic markers to identify the mutant cells.

\section{Early studies of developmental genes with chimeras}

Mutations in Mip, the major intrinsic protein of eye lens fibres, cause congenital cataracts. Chimeras were generated composed of cells from wild-type mice and cells from either the Cat ${ }^{F r}$ (Cataract Fraser now known as Mip Cat ${ }^{-F}$ ) or the Lop (cataract lens opacity, now Mip Cat-Lop) mouse mutations (Muggleton-Harris et al., 1987; Shiels etal., 1991). A transposon-induced splicing error introduces a long repeat sequence replacing the normal Mip carboxy terminus in Mip Cat-Fr, whereas a $G$ to $C$ transversion at position 151 of the encoded MipCat-Loo mRNA inhibits targeting to the cell-membrane. Muggleton-Harris et al. (1987) produced adult Mip Cat-Fr/Mip Cat-Fr $\leftrightarrow$ $+1+$ chimeras and estimated the contribution of mutant cells to the lenses by GPI electrophoresis (as described earlier). Lenses composed entirely of mutant cells were cataractous but none of the chimeric lenses had congenital cataracts, even when mutant cells predominated. Similarly, the severely dysgenic lens fibre pheno- type in LOP mice could be partly corrected in Mip Cat-Lop/Mip Cat-Lop $\leftrightarrow t /+$ chimeras (Shiels et al., 1991). These results suggested a non-autonomous effect whereby wild-type cells corrected the congenital cataractous phenotype usually associated with the mutants. This phenotypic rescue was incomplete because some lenses developed abnormalities after 2 months.

In addition Yoshiki et al. (1991) studied the role of the eye lens obsolescence gene Elo, (Cryge-crystallin gamma E (Cartier etal., 1992)) and showed that a mixture of normal and Elo/+developing lens fibres (with abnormal nuclei) occur together in the posterior of the developing Elol $+\leftrightarrow+/+$ lens. The chimeric lenses were often morphologically similar to non-chimeric Eld+ lenses, and it was concluded that there are autonomous roles for Eloduring lens fibre differentiation and elongation, but that Eloprobably did not affect lens epithelial proliferation. All the above results suggested that as expected for a crystalline structure such as the lens, a dysmorphic mutant lens fibre may be supported by surrounding wild-type cells, but equally it may disrupt the normal crystalline arrangement of the surrounding wild-type cells.

Other early experiments with mouse and rat chimeras revealed distinct modes of action for different retinal degeneration mutations (West, 1999). Patches of normal and degenerate photoreceptors (outer nuclear layer; ONL) were seen in $r d / r d \leftrightarrow+/+$ and $R d s / t \leftrightarrow$ $+/+$ mouse chimeras and in $r d y / r d y \leftrightarrow+/+$ rat chimeras. $R d s$ is the mouse retinal degeneration slow gene, which affects both homozy- 
gotes and heterozygotes, and $r d$ is the mouse retinal degeneration gene (now known as Pde6b, phosphodiesterase 6B). The rat retinal dystrophy gene $(r d y)$ causes a similar phenotype to mouse $r d$ and $R d s$, however, chimera experiments showed that the mode of action differed significantly. No spatial relationships were seen between patches of pigmented and albino cells in the RPE and patches of degeneration in the ONL for the mouse $r d / r d k+t+$ and $R d s / \leftrightarrow+/+$ chimeras (LaVail and Mullen, 1976; Sanyal et al., 1986; also see Fig. 2C). Hence the $r d(P d e 6 b)$ and $R d s$ genes act in the neural retina rather than the RPE. However, $r d y / r d y \leftrightarrow+/+$ rat chimeras showed that the ONL degenerated only in regions that were adjacent to patches of RPE comprising rdy/rdycells (Mullen and LaVail, 1976) showing that the primary defect was in the overlying RPE and not in the neural retina itself. Thus the $r d y$ mutant RPE cells induces degeneration in the adjacent neural retina cells in a non-autonomous fashion.

Further analysis of mouse retinal degeneration focused on the mis-expression of a pig rhodopsin transgene; the transgenic expression both caused the $r d$ phenotype and provided a convenient marker for affected cells detected by RNA in situhybridisation (Huang et al., 1993). This revealed patchy distributions of transgenic and wild-type cells in the neural retina but, unlike the retinal degeneration chimeras discussed above, the ONL did not show patchy distributions of degeneration. The chimeras had a uniform ONL of intermediate thickness implying uniform degeneration of both wild-type and transgenic photoreceptor cells. These observations suggested that the transgene acted non-autonomously, and that within the ONL cell interactions are crucial. The chimera experiments thus revealed an unknown complexity for generating retinal degeneration and uncovered a third mechanism that is distinct from the two identified by earlier chimera experiments with mutant genes.

\section{Use of transgenic lineage markers to study developmental genes in chimeras}

The cloning of genes underlying classical mutations and the availability of transgenic lineage markers have been crucial in extending the range of mouse chimeras in which conditions 1 and 3 above can be fulfilled, and have increased the power of chimeric analysis.

Lens development. The $T g(H b b-b 1) 83 C / o \beta$-globin transgene (incorporated into the genome as approximately a thousand contiguous copies) was used by Liégeois et al. (1996) in examining the action of the recessive aphakia (ak) mutation. Homozygous $a k / a k$ mice do not develop lenses and $a k$ is almost certainly an allele of Pitx3(Semina et al., 2000; Rieger et al., 2001). The route for chimera production entailed the injection of wild-type ES cells carrying the $\mathrm{Tg}(\mathrm{Hb} b-\mathrm{b} 1) 83 \mathrm{Cl} / \mathrm{\beta}$-globin transgene into aklak blastocysts. Chimeric animals manifested normal lenses that, however, were entirely derived from the $\mathrm{Tg}^{+} \mathrm{ES}$ (wildtype) cells showing that akgene function is autonomously required during lens development.

Similar results were obtained for analysis of the roles of the transcription factor Pax6 in the lens. Pax 6 is expressed strongly throughout eye development, in the undifferentiated optic vesicle and optic cup (in both the RPE and all neural retina precursors), in the facial epithelium, lens placode and developing lens and the epithelial layers of the iris and cornea (Walther and Gruss, 1991). Eye development fails at very early stages in the homozygous mutants (the interaction between the optic vesicle and facial epithelium, which leads to the induction of the lens placode, does not occur). Hence although the homozygous mutants do not develop lenses, it was not immediately clear whether this was due to an autonomous requirement for Pax6 in the developing lens lineage or a failure of lens induction by the optic vesicle. Quinn et al. (1996) showed that lenses normally developed in the eyes of $\mathrm{Pax}^{+/+} \leftrightarrow \mathrm{Pax}^{-/-}$chimeras that contained less than $\sim 50 \%$ mutant cells, but that no Pax ${ }^{-/}$cells were ever detected in those lenses by in situ hybridisation against the $T g(H b b-b 1) 83 C / o \beta$-globin transgene (Fig. 6A). It could therefore be concluded that Pax6 is required in a cell autonomous manner for normal contribution to the lens.

A similar conclusion was drawn from Mab21/1+1+ $\leftrightarrow$ Mab21/1 \% aggregation chimeras (Yamada et al., 2003). Mab21/1 is expressed in both the optic vesicle and the lens placode, and Mab21/1-mice are aphakic. Mutant cells did not contribute to the chimeric lens, showing an autonomous requirement for Mab21/1. The results are consistent with the observed down-regulation of Mab21/1 in Pax ${ }^{-/}$mutants, and suggest a genetic network for lens formation in which Mab21/1 expression is downstream of Pax6.

Retinal development. Presence/absence of a particular cell type in a chimeric tissue is only one of many possible 'end-points' of a cell autonomous role for a developmental gene. Mutant cells may be incorporated into a chimeric tissue, but be dysgenic (like the Elo/+lens fibre nuclei described above). Alternatively, if the gene controls parameters of proliferation, mutant cells may be over or under-represented in a chimeric tissue (in comparison to the global composition of the chimera). For example Robanus Maandag et al. (1994) found apparent selection against $R b^{-/}$cells in the retina of $R b^{+/+} \leftrightarrow R b^{-/}$chimeras, by comparing the GPI1A:1B ratio of the retina with that of the other tissues in the chimera.

If a gene autonomously controls cell surface properties of the tissues in which it is expressed, then mutant cells may be present in normal numbers in those tissues in chimeras, but may fail to develop normally or may show patterns of segregation within or physical budding from those tissues. This is the case for Pax6 ${ }^{-1-}$ cells in the developing neural retina. During the interaction between the optic vesicle and the prospective epithelium in E9.5 Pax6 $6^{+/+} \leftrightarrow$ Pax6 $^{-/}$chimeras, the mutant cells are physically excluded and may form small ectopic vesicles abutting a primarily wild-type distal optic vesicle (Collinson et al., 2000) (Fig. 6B). In chimeras that are $>50 \%$ mutant cells, contribution of $\mathrm{Pax}^{-/}$cells to the convoluted chimeric neural retinal tissue continues to at least E16.5, but there is almost complete segregation of $\mathrm{Pax}^{+/}$ + and Pax $^{-/-}$cells into blocks of cells of a single genotype (Fig. 6 C,D) (Quinn et al., 1996; Collinson et al., 2000). Pax6 controls a number of cell surface and adhesion molecules (reviewed in Simpson and Price, 2002), and differential expression of subsets of these molecules in wild-type and mutant cells may explain their autonomous segregation in some chimeric tissues.

'Developmental delay' is another end-point of autonomous gene function that may be discerned in chimeras. Pax $6^{-/}$cells contribute to the developing retinal pigment epithelium of $\mathrm{Pax}^{+/+}$ $\leftrightarrow$ Pax $6 \%$ chimeras, but in contrast to wild-type cells are not pigmented at E12.5 (Quinn et al., 1996). However, by E16.5, some pigmented Pax $^{\%}$ cells are found in the chimeric RPE (Fig. 6E) (Collinson et al., 2003), showing that Pax6 is not absolutely 
required for differentiation, but alternatively, controls the timing of the genetic cascade that leads to pigmentation.

\section{Early embryonic lethality and developmental failure}

Chimeric analysis of mouse mutants allows an understanding of gene function in tissues for which the mutation normally disrupts development at an early stage. For example, Pax6 is expressed in the cornea, but eye development fails before corneal induction in $\mathrm{Pax}^{-/}$mice. Collinson et al. (2003) used chimeras to investigate the roles of Pax6 in the developing cornea. Pax6 is expressed at high levels in the corneal epithelium and perhaps, not surprisingly, mutant cells did not contribute to the corneal epithelium of Pax $^{+/+} \leftrightarrow$ Pax $^{-/}$chimeras. Less expected was a significant, though less dramatic, under-representation of Pax $\%$ cells in the corneal stroma and endothelium of E16.5 chimeras, detected by comparing the proportion of $\mathrm{Tg}(\mathrm{Hbb}-b 1) 83 \mathrm{Cl} \mathrm{O}^{+} \mathrm{Pax}^{-1}$ cells in the different corneal layers with the global composition of the chimera determined by GPI in non-ocular tissues. The corneal stroma and endothelium express Pax 6 at very low levels (barely detectable by immunohistochemistry) transiently in the late-fetal and perinatal stages. The autonomous under-representation of $\mathrm{Pax6}^{-1}$ cells in these tissues was therefore good genetic evidence that the very weak detected expression may have functional significance during corneal development.

Nottoli etal. (1998) and West-Mays etal. (1999) used chimeras to study the developmental roles of the transcription factor, AP$2 \alpha$. Knockout $A P-2 \alpha \%$ mice show perinatal lethality, with dysgenesis of many organ systems. Severe craniofacial dysgenesis, including microphthalmia or anophthalmia were reported. Nottoli et al. (1998) and West-Mays et al. (1999) made chimeras by injection of $A P-2 \alpha \%$ ES cells into wild-type blastocysts. The chimeras showed ocular dysmorphologies including retinal and lens defects. A proportion of the chimeras showed eye defects in the absence of other craniofacial defects, dissociating abnormalities of the eye from secondary consequences manifested by the head abnormalities. The persistence of a lens-corneal bridge in many chimeras correlated with the presence of $A P-2 \alpha^{-/}$cells (expressing lac $Z$ in the lens stalk, suggesting an autonomous role for $A P$ - $2 \alpha$ in the morphogenesis of the lens vesicle (Fig. 6 F,G).

Taken a step further, it is possible to identify roles for important developmental genes during maintenance and ageing of adult tissues in chimeras, when conventional knockouts are embryonic lethal. This is of likely relevance to the study of oncogenes and tumour suppressors. Robanus Maandag etal. (1994) used chimeras to study the role of the $R b$ gene in adult ocular tissues. $R b^{-/}$knockout embryos die at E13-E15 and this lethality is mediated via the placenta (Wu et al., 2003). However, $R b^{-}$cells contributed to most adult chimeric tissues. There was failure of $R b^{-/}$lens cell differentiation in the chimeras, and ectopic proliferation of retinoblasts, suggesting a failure of $R b^{-}$cells to respond to differentiation and growth-arrest signals. Liégeois et al. (1996) used their 'lens complementation assay' described above to investigate the role of $\mathrm{Rb}$ in the lens. Injection of $R b^{-/}$ES cells into ak/akblastocysts produced chimeric mice in which the lenses were entirely composed of $R b^{-/}$cells. The lens fibres were disorganised with a large number of nuclei abnormally situated in the lens fibre region, some of which were mitotic.

\section{Dissection of tissue-tissue interactions}

Chimeras have been used to elucidate the functions of a developmental gene in tissue-tissue interactions in a situation in which both interacting tissues each express the gene of interest. Collinson et al. (2000) took advantage of the tendency of Pax $6^{+/+}$and Pax ${ }^{-/-}$cells to segregate in chimeric tissues to analyse the interface between the optic vesicle and the facial epithelium (prospective lens placode) in E9.5 mouse chimeras. Areas of the optic vesicle/prospective lens interface were identified where both tissues were wild-type, both mutant, or one tissue was mutant and the other wild-type. Lens placode formation and contact between the optic vesicle and the facial epithelium were scored. A strong correlation between the genotype of the facial epithelium and lens placode formation was found, showing that only Pax6 ${ }^{+/+}$epithelium developed a placodal thickening and confirming the autonomous role of Pax6 in the process of lens induction. A second significant correlation was found, highlighting the role of Pax 6 in establishing and maintaining the adhesion at the interface between the optic vesicle and lens placode; Pax $6^{+1+}$ sectors of optic vesicle tended to maintain the contact whereas $\mathrm{Pax}^{-1}$ sectors lost contact (Fig. 6C). This recapitulated the failure of the optic vesicle and facial epithelium to maintain contact in the non-chimeric Pax6 ${ }^{-/}$E9.5 embryo. Thus PaxGis required in both the optic vesicle and the facial epithelium to establish the full contribution of inductive and morphogenetic events that drive early eye development. Pax6 is required in the optic vesicle to maintain the adhesion during lens induction, and in the facial epithelium to autonomously control the genetic pathways that lead to lens differentiation.

\section{Subtle developmental defects revealed by chimeric analysis}

Collinson et al. (2001) showed that although Pax6 ${ }^{+/-}$heterozygotes develop lenses, heterozygous cells are eliminated from the lens epithelium of $\mathrm{Pax6}^{+/+} \leftrightarrow \mathrm{Pax}^{+/-}$chimeras between E12.5 and E16.5, leading to the production of a wildtype lens, even in chimeras highly enriched (up to $80 \%$ ) in $\mathrm{PaxG}^{+/-}$cells. Although lens development is delayed in non-chimeric $P a x 6^{+/-}$mice, there are no discernable defects, at the level of analysis of proliferation or apoptosis in heterozygous lenses, that might explain the complete 'disappearance' of $\mathrm{Pax}^{+/-}$cells in chimeras.

A study of the localisation of Pax6 ${ }^{+/}$cells in the chimeric lens epithelia at E12.5, however, revealed that they were primarily distributed at the lateral edge of the lens epithelium, close to the lens equator. This suggests there may be some subtle adhesive or migratory defect of the Pax $6^{+/}$cells such that they are more likely than wild-type to be eliminated from the mid-lateral proliferative zone of the lens epithelium, and to move to the edge where cells leave the epithelium, become post-mitotic and differentiate.

Furthermore, it was noted that in adult Pax6 ${ }^{+/+} \leftrightarrow$ Pax $^{+/-}$ chimeras, composed of up to $80 \%$ heterozygous cells but (as described above) with wild-type lenses, no other anterior segment defects were noted. The other eye tissues developed normally even though they were predominantly composed of $\mathrm{Pax}^{+/-}$cells. The lens is a primary organiser for anterior segment development (Thut et al., 2001; Strickler et al., 2001), and the data from the chimeras suggested that if Pax6 dosage was restored in the lens, it could nonautonomously correct the mutant phenotype in surrounding tissues.

\section{Chimeras, mosaics and tissue recombinations}

The production of chimeras provides information about the in vivo development of complex organ structures. At a descriptive level, the analysis of the distribution of mutant cells in chimeras generates functional hypotheses about gene function that can be 
tested further by molecular techniques. Chimeras are particularly useful for studying the roles of developmental genes in organs or tissues that do not form in conventional gene knockout mice, perhaps because of embryonic lethality, and they facilitate dissection of complex tissue-tissue interactions by allowing analysis of different roles for the same gene in interacting tissues. However, several other technologies exist that can be used to address these issues, and chimeras may not always be the most appropriate tool. Under what circumstances can similar information about ocular development be obtained by other, perhaps less labour intensive, techniques?

In vitro tissue recombinations can recapitulate many of the in vivo chimeric situations. If two tissues that express a developmental gene interact during normal morphogenesis, it may be possible in culture to study the interactions in a reconstituted system where one tissue is mutant and the other wild-type. In vitro experiments may produce data of equal or better quality, compared to chimeras, by achieving greater control of the genotype and arrangement of interacting tissues, but are only informative if culture systems are available that allow one to recapitulate a physiological situation. While culture systems exist for most ocular cell types, it is not yet possible to recombine a developing eye from its component tissues in vitro. Even if it were, there are still biologically important factors, such as the physical stresses of rapid three-dimensional craniofacial morphogenesis that are difficult if not impossible to reproduce in tissue culture. For example, Fujiwara et al. (1994) studied the roles of PaxGin the optic vesicle and lens placode by performing reciprocal recombinations of Pax $^{\%}$ facial epithelium with wildtype optic vesicle, and vice versa. They found that the genotype of the facial epithelium determined whether or not an invaginating lens placode would form, but that both $\mathrm{Pax}^{+1+}$ and Pax6 ${ }^{-1}$ optic vesicles were capable of inducing lens development. This contrasted with the $\mathrm{Pax}^{+/+} \leftrightarrow \mathrm{Pax}^{-1-}$ chimeric eyes in Collinson et al. (2000), which suggested that both optic vesicle and facial epithelium had to be $\mathrm{Pax}^{+/+}$for lens morphogenesis to occur. Although Pax6 may not have a role in producing lens-inducing signals in the optic vesicle (Furuta and Hogan, 1998), it is required in the optic vesicle to maintain the adhesion with the facial epithelium, which may be necessary for mediation of (non-Pax6 dependent) lensinduction. This role is not apparent in vitro because the adhesion between the two tissues is maintained irrespective of the genotype of the optic vesicle.

Conditional gene inactivation using Cre-loxP or similar systems enables induction of mosaicism in defined tissues at specific stages in development. Once the conditional mutation is created there is (unlike chimeras) no further requirement for embryonic manipulation to produce the experimental animal. The Cre-loxP technology requires the site-directed insertion of two loxP recombinase target sites into the gene whose activity is to be eliminated. In order to conditionally disrupt the gene the Cre recombinase (from bacteriophage P1) is expressed from a tissuespecific promoter. Conditional mutations, thus far, have been used sparingly in the study of eye development. However, it is clear that the approach provides a different genetic perspective in understanding the developmental process.

Ashery-Padan et al. (2000) expressed Cre from elements of the Pax6 promoter that drive expression in the lens, cornea and pancreas. The floxed Pax6 allele was knocked out in the surface ectoderm of the head, leading to failure of lens development. The retina of these mice was convoluted at E14.5, with more than one

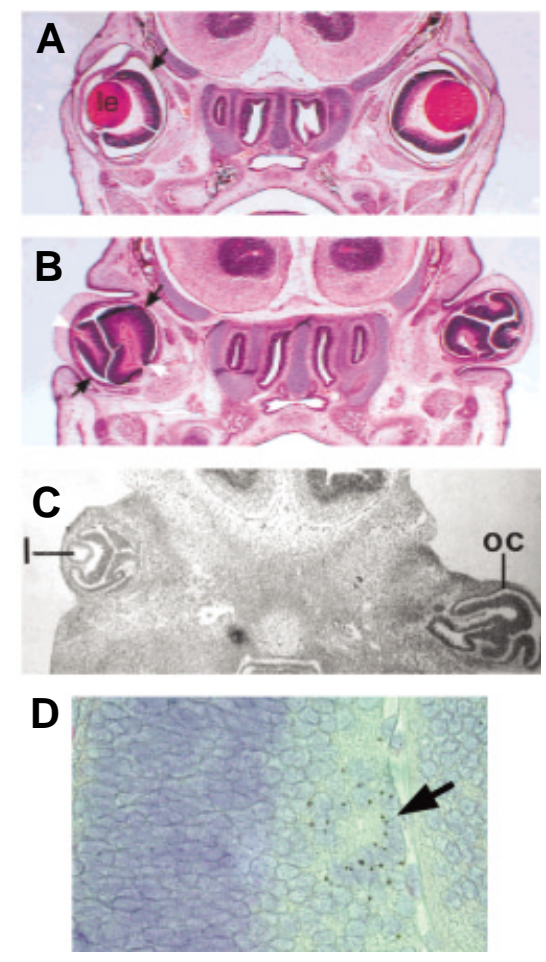

Fig. 7. Comparison of eye phenotypes produced in conditional knockouts and chimeras. $(A, B)$. Coronal section of head of E14.5 control embryo (A) contrasts with the absence of a lens and presence of multiple convoluted neuroretinae in the Pax6 lens-specific conditional knockout (B). (A, B. reproduced with permission from Ashery-Padan et al., 2000). (C). Superficially similar section of an E12.5 Pax6 ${ }^{+/+} \leftrightarrow \mathrm{Pax} 6^{-1}$ chimera. The right eye lacks a lens and has multiple convoluted neuroretinae. (Reproduced from Quinn et al., 1996). (D). Pax6 ${ }^{-1}, \mathrm{Tg}^{+}$cells in the prospective ganglion cell layer of an E16.5 Pax6 ${ }^{+/+} \leftrightarrow \mathrm{Pax}^{-1-}$ chimera (arrow). (Reproduced from Collinson et al., 2003). Key: I, lens; le, lens; oc, optic cup.

optic nerve head in each eye, suggesting that several retinae were developing (Fig. 7 A,B). Molecular markers demonstrated that the patterning of these convoluted neuroretinae was normal. Quinn et al. (1996) produced superficially similar eyes in $\mathrm{Pax}^{+1+} \leftrightarrow \mathrm{Pax}^{-1}$ chimeras with a high proportion of mutant cells (Fig. 7C). Both the chimeras and the Cre-/oxPlens knockouts demonstrated a requirement for Pax 6 in the lens. In contrast they provided different information about the retina - the segregation of $\mathrm{Pax}^{+/+}$and $\mathrm{Pax}^{-/}$cells in the chimeras suggested adhesive defects in the mutant neuroretina, which was not determined from the Cre-loxPretinae. However, the chimeras provided less information about the development of the wild-type retinal cells in absence of a lens, partly because of the complication of having both mutant and wild-type cells in the same tissue.

Marquardt et al. (2001) used the Pax6 $\alpha$-regulatory element to drive Cre expression in the distal neuroretina from E10.5. Retinal precursors normally express Pax 6 and are pluripotent, capable of differentiating into 6 neuronal cell types, and Müller glia, in the mature retina. Pax $6^{-1}$ retinal precursors in the conditional knockouts expressed markers characteristic of amacrine cells only. In contrast, Pax $6^{-/}$cells in the retina of $\mathrm{Pax}^{+/+} \leftrightarrow \mathrm{Pax}^{-}$chimeras at E16.5 (Collinson etal., 2003) were almost entirely confined to the prospective ganglion cell layer (Fig. 7D). This apparent discrepancy is possibly due to the different timing of Pax6 inactivation in 
the chimeras and conditional knockouts. Pax6 was inactivated at E10.5 by Marquardt et al. (2001), by which time the distal optic cup has been specified as neural retina; its subsequent differentiation reflects the fate of retinal precursors with or without Pax6. In the chimeras, the Pax6-negative retinal cells have never expressed Pax6, and the Pax ${ }^{\%}$ cells in the chimeric ganglion layer may represent an earlier 'pre-retinal' stage of optic vesicle differentiation, expressing different cell surface markers from the amacrine cells in the conditional knockout.

In comparison to chimeras, Cre-/oxPconditional knockouts are more reproducible and, for some purposes, may provide 'cleaner' experiments in that they can produce in vivo tissue combinations where all the cells of one tissue are mutant from particular stages of development, while surrounding tissues remain wild-type. Generally, the rate-limiting step for Cre-loxP investigations has been the availability of reliable promoters that drive Cre expression in the required temporal and tissue-specific patterns. In the eye, promoter dissection of important genes such as Pax6and crystallins allows the cloning of regulatory elements to drive Cre expression. Nevertheless, until promoter elements are cloned to cover all ocular cell types, the production of chimeras may remain the best way of getting a mixture of mutant cells into some ocular tissues.

Intimate mixing of wild-type and mutant cells within a single chimeric tissue provides information about cell-cell signalling and the autonomous cellular consequences of gene mutation in vivo that is not normally achieved in Cre-loxP conditional knock-outs. For example, in the Pax $6^{+1+} \leftrightarrow$ Pax $^{\%}$ chimeras produced by Quinn et al. (1996), lenses (derived entirely from wild-type cells) developed in chimeras that were less than $\sim 50 \%$ mutant cells, but not in those that were primarily composed of mutant cells. This suggested some sort of lens community effect or that a minimum essential 'cohort' of wild-type facial epithelium is required to maintain normal lens development. Mosaic patterns of gene inactivation within a single tissue are possible with Cre-loxP, e.g. by use of a weak promoter to drive Cre expression. A tamoxifeninducible system for Cre expression has been demonstrated, which may also produce mosaic patterns of floxed gene inactivation in a single tissue (Hayashi and McMahon, 2002). Although we have yet to see widespread application of the tamoxifen-inducible system for this purpose, we believe it may combine the versatility and elegance of chimeric systems with the controllability and reproducibility of Cre-loxP.

\section{Acknowledgements}

We thank Drs Takayuki Nagasaki, Judith West-Mays and Benjamin Reese for kindly providing electronic versions of some figures and we are grateful to the Medical Research Council, Wellcome Trust and Scottish Hospitals Endowments Research Trust for financial support for our own research. We apologise to the authors whose work, for reasons of space, we have not been able to include.

\section{References}

ASHERY-PADAN R., MARQUARDT, T., ZHOU, X., and GRUSS, P. (2000). Pax6 activity in the lens primordium is required for lens formation and for correct placement of a single retina in the eye. Genes Dev. 14: 2701-2711.

BETZ, U. A. K., VOSSHENRICH, C. A. J., RAJEWSKY, K. and MÜLLER, W. (1996). Bypass of lethality with mosaic mice generated by Cre-loxP-mediated recombination. Curr. Biol. 6: 1307-1316.

BODENSTEIN, L. (1986). A dynamic simulation model of tissue growth and cell patterning. Cell Differ. 19: 19-33.
BODENSTEIN, L. and SIDMAN, R. L. (1987a). Growth and development of the mouse retinal pigment epithelium. I. Cell and tissue morphometrics and topography of mitotic activity. Dev. Biol. 121: 192-204.

BODENSTEIN, L. and SIDMAN, R. L. (1987b). Growth and development of the mouse retinal pigment epithelium. II. Cell patterning in experimental chimeras and mosaics. Dev. Biol. 121: 205-219.

BRILLIANT, M. H., GONDO, Y. and EICHER, E. M. (1991). Direct molecular identification of the mouse pink-eyed unstable mutation by genome scanning. Science 252: 566-569.

CARTIER, M., BREITMAN, M. L. and TSUI, L. C. (1992). A frameshift mutation in the gamma-E-crystallin gene of the ELO mouse. Nature Genet. 2: 42-45.

CATTANACH, B. M. (1961). A chemically-induced variegated type position effect in the mouse. Z. VererbLehre 92: 165-182.

CEPKO, C. L., AUSTIN, C. P., YANG, X. J. and ALEXIADES, M. (1996). Cell fate determination in the vertebrate retina. Proc. Natl. Acad. Sci. USA. 93: 589-595.

CHAPMAN, V. M., ANSELL, J. D. and McLAREN, A. (1972). Trophoblast giant cell differentiation in the mouse: expression of glucose phosphate isomerase (GPI-1) electrophoretic variants in transferred and chimeric embryos. Dev. Biol. 29: 48-54.

COLLINSON, J. M., HILL, R. E. and WEST J. D. (2000). Different roles for Pax6 in the optic vesicle and facial epithelia mediate early morphogenesis of the murine eye. Development 127: 945-956.

COLLINSON, J. M., QUINN, J. C., BUCHANAN, M. A., WEDDEN, S. E., KAUFMAN M. H., WEST, J. D. and HILL, R. E. (2001). Primary defects in the lens underlie complex anterior segment abnormalities in the Pax6heterozygous eye. Proc. Nat/. Acad. Sci. USA 98: 9688-9693.

COLLINSON, J. M., MORRIS, L., REID, A. I., RAMAESH, T., KEIGHREN, M. A., FLOCKHART, J. H., HILL, R. E., TAN, S.-S., RAMAESH, K., DHILLON, B. and WEST, J. D. (2002). Clonal analysis of patterns of growth, stem cell activity and cell movement during the development and maintenance of the murine corneal epithelium. Dev. Dyn. 224: 432-440.

COLLINSON, J. M., QUINN, J. C., HILL, R. E. and WEST, J. D. (2003). The roles of Pax6 in the cornea, retina and olfactory epithelium of the developing mouse embryo. Dev. Biol. 255: 303-312.

DEOL, M.S. and WHITTEN, W.K. (1972). Time of $X$ chromosome inactivation in retinal melanocytes of the mouse. Nature New Biology238, 159-160.

DOBIE, K., MEHTALI, M., McCLENAGHAN, M. and LATHE, R. (1997). Variegated gene expression in mice. Trends Genet. 13: 127-130.

EGGAN, K., AKUTSU, H., HOCHEDLINGER, K., RIDEOUT, W., YANAGIMACHI, R. and JAENISCH, R. (2000). X-chromosome inactivation in cloned mouse embryos. Science 290: 1578-1581.

FRIEDRICH, G. and SORIANO, P. (1991). Promoter traps in embryonic stem cells: a genetic screen to identify and mutate developmental genes in mice. Genes Dev. 5: 1513-1523.

FUJIWARA, M., UCHIDA, T., OSUMI-YAMASHITA, N. and ETO, K. (1994). Uchida rat ( $r$ Sey): a new mutant rat with craniofacial abnormalities resembling those of the mouse Sey mutant. Differentiation 57: 31-38.

FURUTA, Y. and HOGAN, B. L. M. (1998). BMP4 is essential for lens induction in the mouse embryo. Genes Dev. 12: 3764-3775.

GARDNER, R. L. (1968). Mouse chimaeras obtained by the injection of cells into the blastocyst. Nature 220: 596-597.

GARDNER, R. L. (1984). An in situcell marker for clonal analysis of development of the extraembryonic endoderm in the mouse. J. Embryol. Exp. Morphol. 80: 251 288.

GEARHART, J. D. and MINTZ, B. (1972). Clonal analysis of somites and their muscle derivatives: evidence from allophenic mice. Dev. Biol. 29: 27-37.

HADJANTONAKIS, A. K., GERTSENSTEIN, M., IKAWA, M., OKABE, M. and NAGY, A. (1998a). Generating green fluorescent mice by germline transmission of green fluorescent ES cells. Mech. Dev. 76: 79-90.

HADJANTONAKIS, A. K., GERTSENSTEIN, M., IKAWA, M., OKABE, M. and NAGY, A. (1998b). Non-invasive sexing of preimplantation stage mammalian embryos. Nature Genet. 19: 220-222.

HAYASHI, S. and MCMAHON, A. P. (2002). Efficient recombination in diverse tissues by a tamoxifen-inducible form of Cre: $A$ tool for temporally regulated gene activation/inactivation in the mouse. Dev. Biol. 244: 305-318.

HUANG, P. C., GAITAN, A. E., HAO, Y., PETTERS, R. M. and WONG, F. (1993). 
Cellular interactions implicated in the mechanism of photoreceptor degeneration in transgenic mice expressing a mutant rhodopsin gene. Proc. Natl. Acad. Sci. USA. 90: 8484-8488.

KEIGHREN, M. and WEST, J. D. (1993). Analysis of cell ploidy in histological sections of mouse tissues by DNA-DNA in situ hybridization with digoxygenin labelled probes. Histochem. J. 25: 30-44.

KUSAKABE, M., YOKOYAMA, M., SAKAKURA, T., NOMURA, T., HOSICK, H. L. and NISHIZUKA, Y. (1988). A novel methodology for analysis of cell distribution in chimeric mouse organs using a strain specific antibody. J. Cell Biol. 107: 257-265.

LAVAIL, M. M. and MULLEN, R. J. (1976). Role of the pigment epithelium in inherited degeneration analysed with experiental mouse chimaeras. Exp. Eye Res. 23: 227 245.

LIÉGEOIS, N. J., HORNER, J. W. and DEPINHO, R. A. (1996). Lens complementation system for the genetic analysis of growth, differentiation, and apoptosis in vivo. Proc. Natl. Acad. Sci. USA 93: 1303-1307.

LO, C. (1986). Localization of low abundance DNA sequences in tissue sections by in situ hybridization. J. Cell Sci. 81: 143-162.

LYON, M. F. (1961). Gene action in the X-chromosome of the mouse (Mus musculus L.). Nature 190: 372-373.

MARQUARDT, T., ASHERY-PADAN, R., ANDREJEWSKI, N., SCARDIGLI, R., GUILLEMOT, F., and GRUSS, P. (2001). Pax6 is required for the multipotent state of retinal progenitor cells. Cel/105: 43-55.

MINTZ, B. (1971). Genetic mosaicism in vivo: Development and disease in allophenic mice. Fedn. Proc. 30: 935 - 943.

MINTZ, B. and SANYAL, S. (1970). Clonal origin of the mouse visual retina mapped from genetically mosaic eyes. Genetics 64 : 43-44.

MUGGLETON-HARRIS, A. L., HARDY, K. and HIGBEE, N. (1987). Rescue of developmental lens abnormalities in chimeras of noncataractous and congenital cataractous mice. Development 99: 473-480.

MULLEN, R. J. (1978). Mosaicism in the central nervous system of mouse chimaeras. In The Clonal Basis of Development (S. Subtelny and I. M. Sussex, Eds.), pp. 82101. Academic Press, New York.

MULLEN, R. J. and LAVAIL, M. M. (1976). Inherited retinal dystrophy: primary defect in pigment epithelium determined with experimental rat chimaeras. Science192: 799-801.

NAGASAKI, T. and ZHAO, J. (2003). Centripetal movement of corneal epithelial cells in the normal adult mouse. Invest. Ophthal. Vis. Sci. 44: 558-566.

NESBITT, M. N. (1974). Chimaeras vs. X inactivation mosaics: significance of differences in pigment distribution. Dev. Biol. 38: 202-207.

NICOLAS, J. F., MATHIS, L. and BONNEROT, C. (1996). Evidence in the mouse for self-renewing stem-cells in the formation of a segmented longitudinal structure, the myotome. Development 122: 2933-2946.

NOTTOLI, T., HAGOPIAN-DONALDSON, S., ZHANG, J., PERKINS, A. and WILLIAMS, T. (1998). AP-2-null cells disrupt morphogenesis of the eye, face, and limbs in chimeric mice. Proc. Natl. Acad. Sci. USA 95: 13714-13719.

PONDER, B. (1987). Cell marking techniques and their application. In Mammalian Development: A Practical Approach (M. Monk, Ed.), pp. 115-138. IRL Press, Oxford.

PRATT, T., SHARP, L., NICHOLS, T., PRICE, D. J. and MASON, J. O. (2000). Embryonic stem cells and transgenic mice ubiquitously expressing a tau-tagged green fluorescent protein. Dev. Biol. 228: 19-28.

QUINN, J. C., WEST, J. D. and HILL, R. E. (1996). Multiple functions for Pax6in mouse eye and nasal development. Genes Dev. 10: 435-446.

REESE, B. E., HARVEY, A. R. and TAN, S. S. (1995). Radial and tangential dispersion patterns in the mouse retina are cell-class specific. Proc. Natl. Acad. Sci. USA. 92: 2494-2498.

REESE, B. E., NECESSARY, B. D., TAM, P. P. L., FAULKNER-JONES, B. and TAN, S. S. (1999). Clonal expansion and cell dispersion in the developing mouse retina. Eur. J. Neurosci. 11: 2965-2978.

REESE, B. E. and TAN, S. S. (1998). Clonal boundary analysis in the developing retina using X-inactivation transgenic mosaic mice. Semin. Cell Dev. Biol. 9: 285-292.

REICHENBACH, A., ZIEGERT, M., SCHNITZER, J., PRITZHOHMEIER, S., SCHAAF, P., SCHOBER, W. and SCHNEIDER, H. (1994). Development of the rabbit retina. V. The question of columnar units. Dev. Brain Res. 79. 72-84.
RIEGER, D. K., REICHENBERGER, E., MCLEAN, W., SIDOW, A. and OLSEN, B. (2001). A double-deletion mutation in the Pitx3 gene causes arrested lens development in aphakia mice. Genomics 72: 61-72.

ROACH, S. A. (1968). "The Theory of Random Clumping." Methuen, London. 94pp.

ROBANUS MAANDAG, E. C., VAN DER VALK, M., VLAAR, M., FELTKAMP, C., O'BRIEN, J., VAN ROON, M., VAN DER LUGT, N., BERNS, A. and TE RIELE, $H$. (1994). Developmental rescue of an embryonic-lethal mutation in the retinoblastoma gene in chimeric mice. EMBO J. 13: 4260-4268.

ROSSANT, J. and CHAPMAN, V. M. (1983). Somatic and germline mosaicism in interspecific chimeras between Mus musculus and Mus caroli. J. Embryol. Exp. Morphol. 73: 193-205

ROSSANT, J. and SPENCE, A. (1998). Chimeras and mosaics in mouse mutant analysis. Trends Genet. 14: 358-363.

SANYAL, S. and ZEILMAKER, G.H. (1977). Cell lineage in retinal development of mice studied in experimental chimaeras. Nature 265: 731-733.

SANYAL, S., DEES, C. and ZEILMAKER, G. H. (1986). Development and degeneration of retina in $r d s$ mutant mice: observations in chimaeras of heterozygous mutant and normal genotype. J. Embryol. Exp. Morphol. 98: 111-121.

SCHMIDT, G. H., WILKINSON, M. M. and PONDER, B. A. J. (1986). Non-random spatial arrangement of clone sizes in chimaeric retinal pigment epithelium. J. Embryol. Exp. Morph. 91: 197-208.

SEMINA, E. V., MURRAY, J. C., REITER, R., HRSTKA, R. F. and GRAW, J. (2000). Deletion in the promoter region and altered expression of Pitx3homeobox gene in aphakia mice. Hum. Mol. Genet. 9: 1575-1585.

SHIELS, A., GRIFFIN, C. S. and MUGGLETON-HARRIS, A. L. (1991). Immunochemical comparison of the major intrinsic protein of eye-lens fibre cell membranes in mice with hereditary cataracts. Biochim. Biophys. Acta 1097: 318-324.

SIMPSON, T. I. and PRICE, D. J. (2002). Pax6: a pleiotropic player in development. BioEssays 14: 1041-1051.

SIRACUSA, L. D., CHAPMAN, V. M., BENNETT, K. L., HASTIE, N. D., PIETRAS, D. F. and ROSSANT, J. (1983). Use of repetitive DNA sequences to distinguish Mus musculusand Mus carolicells by in situhybridization. J. Embryol. Exp. Morph73: 163-178.

SORIANO, P. and JAENISCH, R. (1986). Retroviruses as probes for mammalian development: allocation of cells to the somatic and germ cell lineages. Ce//46: 1929.

STRICKLER, A.G., YAMAMOTO, Y. and JEFFERY, W. R. (2001). Early and late changes in Pax6 expression accompany eye degeneration during cavefish development. Dev. Genes Evol. 211: 138-144.

TAN, S.-S., WILLIAMS, E. A. and TAM, P. P. L. (1993). X-chromosome inactivation occurs at different times in different tissues of the post-implantation mouse embryo. Nature Genet. 3: 170-174

TAN, S. S. and BREEN, S. (1993). Radial mosaicism and tangential cell dispersion both contribute to mouse neocortical development. Nature 362: 638-640.

TARKOWSKI, A. K. (1961). Mouse chimaeras developed from fused eggs. Nature 190: $857-860$

THUT, C. J., ROUNTREE, R. B., HWA, M. and KINGSLEY, D. M. (2001). A largescale in situ screen provides molecular evidence for the induction of eye anterior segment structures by the developing lens. Dev. Biol. 231: 63-76.

TURNER, D. L. and CEPKO, C. (1987). Cell lineage in the rat retina: a common progenitor for neurons and glia persists late in development. Nature328: 131-136.

TURNER, D. L., SNYDER, E. Y. and CEPKO, C. L. (1990). Lineage independent determination of cell type in the embryonic mouse retina. Neuron $4: 833-845$.

WALTHER, C. and GRUSS, P. (1991). Pax-6, a murine paired box gene, is expressed in the developing CNS. Development 113: 1435-1449.

WEINBERG, W. C., HOWARD, J. C. and IANNACCONE, P. M. (1985). Histological demonstration of mosaicism in a series of chimeric rats produced between congenic strains. Science 227: 524-527.

WEST, J. D. (1975). A theoretical approach to the relation between patch size and clone size in chimaeric tissue. J. Theor. Biol. 50: 153-160.

WEST, J. D. (1976a). Clonal development of the retinal epithelium in mouse chimaeras and X-inactivation mosaics. J. Embryol. Exp. Morphol. 35: 445-461.

WEST, J. D. (1976b). Distortion of patches of retinal degeneration in chimaeric mice. J. Embryol. Exp. Morphol. 36: 145-149. 
WEST, J. D. (1978a). Analysis of clonal growth using chimaeras and mosaics. In "Development in Mammals" (M. H. Johnson, Ed.), Vol. 3, pp. 413-460. Elsevier, Amsterdam.

WEST, J. D. (1978b). Clonal growth versus cell mingling. In Genetic Mosaics and Chimeras in Mammals (L. B. Russell, Ed.), pp. 435-444. Plenum Press, New York.

WEST, J. D. (1984). Cell markers. In Chimeras in Developmental Biology (N. L. Douarin and A. McLaren, Eds.), pp. 39-63. Academic Press, London.

WEST, J. D. (1999). Insights into development and genetics from mouse chimeras. Curr. Top. Dev. Biol. 44: 21-66.

WEST, J. D. and FLOCKHART, J. H. (1994). Genotypically unbalanced diploid $\leftrightarrow$ diploid foetal mouse chimaeras: possible relevance to human confined mosaicism. Genet. Res. 63: 87-99.

WEST, J. D., HODSON, B. A. and KEIGHREN, M. A. (1997). Quantitative and spatial information on the composition of chimaeric fetal mouse eyes from single histological sections. Dev. Growth Differ. 39: 305-317.
WEST-MAYS, J.A., ZHANG, J., NOTTOLI, T., HAGOPIAN-DONALDSON, S., LIBBY, D., STRISSEL, K.J. and WILLIAMS, T. (2003). AP-2 $\alpha$ transcription factor is required for early morphogenesis of the lens vesicle. Dev. Biol. 206: 46-62.

WILLIAMS, R. W. and GOLDOWITZ, D. (1992). Structure of clonal and polyclonal cell arrays in chimeric mouse retina. Proc. Natl. Acad. Sci. USA. 89: 1184-1188.

WU, L. Z., DE BRUIN, A., SAAVEDRA, H. I., STAROVIC, M., TRIMBOLI, A., YANG, Y., OPAVSKA, J., WILSON, P., THOMPSON, J. C., OSTROWSKI, M. C., ROSOL, T. J., WOOLLETT, L. A., WEINSTEIN, M., CROSS, J. C., ROBINSON, M. L. and LEONE, G. (2003). Extra-embryonic function of $\mathrm{Rb}$ is essential for embryonic development and viability. Nature 421: 942-947.

YAMADA, R., MIZUTANI-KOSEKI, Y., HASEGAWA, T., OSUMI, N., KOSEKI, H. and TAKAHASHI, N. (2003). Cell-autonomous involvement of Mab21/1 is essential for lens placode development. Development 130: 1759-1770.

YOSHIKI, A., HANAZONO, M., ODA, S.-I., WAKASUGI, N., SAKAKURA, T. and KUSAKABE, M. (1991). Developmental analysis of the eye lens obsolescence (E/o) gene in the mouse: cell proliferation and Elo gene expression in the aggregation chimera. Development 113: 1293-1304. 